\title{
Exhaled single-breath nitric oxide measurements are reproducible, repeatable and reflect levels of nitric oxide found in the lower airways
}

\author{
E. Gabbay*+, A.J. Fisher*, T. Small*, A.J. Leonard*+, P.A. Corris*+
}

Exhaled single-breath nitric oxide measurements are reproducible, repeatable and reflect levels of nitric oxide found in the lower airways. E. Gabbay, A.J. Fisher, T. Small, A.J. Leonard, P.A. Corris. CERS Journals Ltd 1998.

ABSTRACT: Measurement of exhaled nitric oxide (NO) may allow noninvasive assessment of inflammatory disease in the lung. We determined immediate and dayto-day reproducibility of single-breath NO measurements at different points on the exhaled test, and whether levels recorded reflect levels of NO in the lower airways.

Using a rapid chemiluminescence analyser, 55 healthy control subjects performed three sequential tests on each of two days. NO levels were compared at the level corresponding with: 1) the time the mouth pressure fell below $4 \mathrm{cmH}_{2} \mathrm{O}(\mathrm{MP}) ; 2$ ) the plateau of end-exhaled $\mathrm{CO}_{2}\left(\mathrm{CO}_{2}\right)$; and 3) the NO plateau (NOp). NO levels were measured directly from the lower airways of 15 lung transplant recipients and compared with NO levels from a single-breath test performed in the same cohort.

For measurements performed at $\mathrm{MP}, \mathrm{CO}_{2}$ and $\mathrm{NOp}$, the mean \pm sD differences between the two closest levels performed on the same day were $0.11 \pm 0.18,0.095 \pm 0.16$ and $0.094 \pm 0.13$ parts per billion (ppb), respectively, and between days were $0.18 \pm 0.76$, $0.19 \pm 0.78$ and $0.17 \pm 0.8 \mathrm{ppb}$, respectively. End-expiratory levels recorded at the mouth from a single-breath test and in the lower airways were highly correlated (mouth versus trachea $\mathrm{r}^{2}=0.95, \mathrm{p}<0.0001$, mouth versus bronchus $\mathrm{r}^{2}=0.92, \mathrm{p}<0.0001$ ).

Single-breath exhaled nitric oxide levels are a simple, reproducible and valid measure of nitric oxide production from the lower respiratory tract. Eur Respir J 1998; 11: 467-472.
Depts of * Respiratory Medicine and ${ }^{+}$Cardiopulmonary Transplantation, Freeman Hospital, Freeman Road, Newcastle upon Tyne, UK.

Correspondence: P.A. Corris

Dept of Respiratory Medicine

Freeman Hospital

Freeman Road

Newcastle upon Tyne

NE7 7DN

UK

Fax: 441912231152

Keywords: Exhaled nitric oxide lower airways nitric oxide levels reproducibility

Received: June 51997

Accepted after revision October 281997

This research was funded by the British Lung Foundation.
Since the observations of FurchgotT and Zawadski [1] that an endothelium derived relaxant factor (EDRF) is required for acetylcholine to exert its vasodilatory effects, and the subsequent identification of EDRF as nitric oxide (NO) [2], the biological significance of this ubiquitous free radical has become increasingly appreciated. In addition to being a potent vasodilator, NO is involved in the regulation of vascular smooth muscle proliferation [3], acts as a neurotransmitter [4], mediates acute inflammation [5] and is an important factor in host defence [6].

When in gaseous phase, NO is relatively stable and highly diffusible [7], so that NO produced in the lung can be measured in exhaled air. Given its biological importance, many authors have postulated that measurement of exhaled NO may allow noninvasive assessment of inflammatory disease in the lung and bronchial tree [8-10] as well as in pulmonary vascular disease [11]. Exhaled NO concentrations are reported to be increased in asthma [8, 9], bronchiectasis [10] and during upper respiratory tract infections in normals [12]. When asthmatics are treated with inhaled corticosteroids, levels return to normal [13] and it has been advocated that exhaled NO measurements be used to monitor the anti-inflammatory effects of new antiasthmatic treatments [14].

However, difficulties remain in the interpretation of exhaled NO measurements. Exhaled NO has been measured by several different poorly standardized techniques. The recent European Respiratory Society (ERS) Task Force guidelines [15] have addressed some of these important issues, yet reproducibility data have been lacking [16]. Much of the difference in reported results may be explained by conflicting methodology $[17,18]$, the different response times and sensitivities of the chemiluminescent analyser used and, for single-breath measurements, at which point along the expiratory breath measurements are made. Measurements of NO previously reported from the lower airways at bronchoscopy, have not been performed with an analyser which is rapid enough to allow on-line measurements during tidal breathing [19] and arguments persist as to how well measurements at the mouth reflect levels in the lower airways [20].

Therefore, in a group of normal controls, we performed a series of standardized single-breath exhaled NO measurements, using a rapid chemiluminescence analyser, to determine the reproducibility of measurements at different points on the exhaled test. As part of a larger study examining exhaled NO after lung transplantation, we also examined the levels of NO in the lower airways of a group of lung transplant recipients using a rapid analyser which allows on-line recordings during tidal breathing. By comparing these measurements with those obtained in the same cohort during a single-breath manoeuvre, we sought to determine if measurements at the mouth reflect levels in the lower airways. 


\section{Materials and methods}

\section{Patient groups}

Healthy, nonsmoking controls without a history of asthma and/or wheeze were taken from hospital staff. To avoid any effects that respiratory infections might have had on NO levels, subjects were free of upper or lower respiratory symptoms on the day of the test and were asked to report the development of any new symptoms within 7 days of their test. In three control patients with unusually high levels, a further follow-up measurement was performed to exclude any change in NO level or the development of respiratory symptoms.

Lower airway measurements were performed on a group of lung transplant recipients who were undergoing surveillance or diagnostic bronchoscopies. To determine the relationship between levels of NO measured at the mouth and in the lower airways, subjects performed a singlebreath test just prior to the bronchoscopy. The study was approved by the regional Ethics Committee.

\section{Nitric oxide analyser}

Exhaled NO was measured using a rapid highly sensitive chemiluminescence analyser (LR2000, version 2.2; Logan Research, Rochester, UK) with a resolution of 0.3 parts per billion (ppb) of NO and response time (0-95\% rise time) of $0.4 \mathrm{~s}$. The analyser also measured $\mathrm{CO}_{2}$ (resolution $0.1 \% \mathrm{CO}_{2}$, response time $0.2 \mathrm{~s}$ ) by single-beam infra-red absorption, mouth pressure, exhaled flow and volume. The sampling rate was $250 \mathrm{~mL} \cdot \mathrm{min}^{-1}$ for all measurements. At this flow rate the delay time was $1.4 \mathrm{~s}$ for the $\mathrm{CO}_{2}$ analyser and $1.8 \mathrm{~s}$ for the NO analyser. The analyser was calibrated daily using medical grade NO at a concentration of $106 \mathrm{ppb}$ in nitrogen (BOC special gases; Surrey Research Park, Guildford, UK) and certified 7.9\% $\mathrm{CO}_{2}$ (Cryoservice; Worcester, UK). Mouth pressure and flow were calibrated using a water manometer and calibration analyser (Timeter RT-200; SLE Ltd., Surrey, UK), respectively. The specifications of the analyser and its maintenance met with the optimum recommendations of the ERS Task Force Guidelines on exhaled NO measurement [15].

\section{Nitric oxide measurements}

Single breath. Following a full inspiration, seated subjects were asked to exhale slowly from total lung capacity through a narrow teflon-coated tube and recordings were made of exhaled $\mathrm{NO}, \mathrm{CO}_{2}$, mouth pressure and exhaled volume (fig. 1). Subjects wore a noseclip and maintained mouth pressure at $4-5 \mathrm{cmH}_{2} \mathrm{O}$ by using biofeedback visual display. At this pressure, the internal nasal route is closed off by the soft palate, thus eliminating nasal NO contamination of the exhaled gas mixture [21]. A constant expiratory flow $\left(250 \mathrm{~mL} \cdot \mathrm{s}^{-1}\right)$ was obtained as exhaled NO concentrations are highly flow dependent [22]. The procedure was repeated until three technically acceptable measurements (based on maintenance of a constant expiratory flow and mouth pressure $>4 \mathrm{cmH}_{2} \mathrm{O}$ for at least three quarters of the

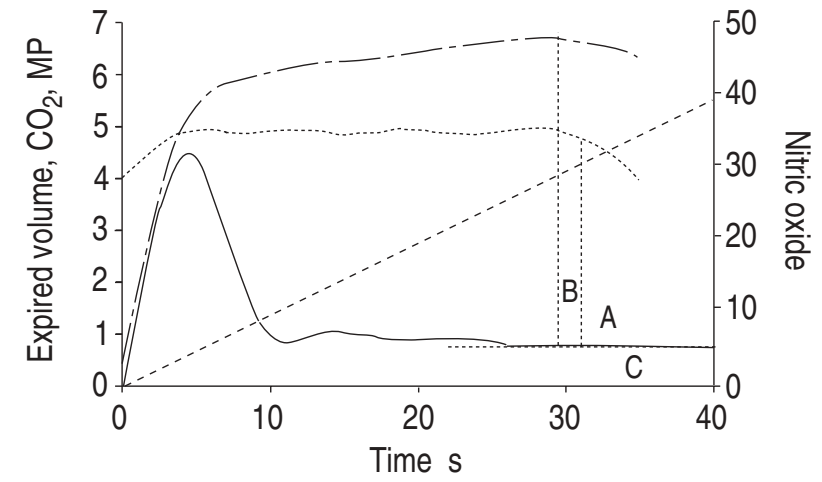

Fig. 1. - Tracings of single-breath exhaled test from total lung capacity showing simultaneous recordings of nitric oxide (parts per billion, exhaled $\mathrm{CO}_{2}(\%,--)$ mouth pressure (MP; $\left.\mathrm{cmH}_{2} \mathrm{O}, \cdots \cdots . ..\right)$ and expired volume $(\mathrm{L},---)$. Tracing showing typical peak and plateau phase and showing points used to measure NO levels: A) when mouth pressure falls below $4 \mathrm{cmH}_{2} \mathrm{O}$; B) when end-exhaled $\mathrm{CO}_{2}$ reaches plateau; and C) when flattest part of exhaled NO plateau achieved.

exhaled breath) were obtained. These series of measurements were repeated in most subjects the following day but in all subjects within 1 week. Ambient NO concentrations were measured daily.

The single breath test is characterized by a short peak followed by a longer plateau phase. The shape of the "plateau" may vary between individuals so that the NO level may differ depending on where the measurement is taken on the exhaled test. To determine the agreement between NO measurements at different points along the "plateau", we recorded the NO level at three physiologically relevant points (A, B and C; fig. 1). Allowing for the different lag times of the respective analysers, we chose the value corresponding to: A) the time the mouth pressure fell below 4 $\mathrm{cmH}_{2} \mathrm{O}(\mathrm{MP})$; B) the plateau of end-exhaled $\mathrm{CO}_{2}\left(\mathrm{CO}_{2}\right)$; and $\mathrm{C}$ ) the NO level corresponding to the longest horizontal line (plateau) of the NO measurement (NOp). These points were used because we felt that (B) and (C) were likely to best represent lower airway measurements and because these points have been used by different authors in reporting NO levels. Point (A) was chosen so that we could determine if there was a significant rise in NO levels after mouth pressure and flow rate fell towards the end of exhalation.

Bronchoscopic. Measurements of $\mathrm{NO}$ and $\mathrm{CO}_{2}$ were simultaneously made from the lower airways of a group of lung transplant recipients who were undergoing surveillance or diagnostic bronchoscopies. Subjects were premedicated with midazolam and local anaesthesia was obtained with $4 \%$ lignocaine. Noseclips were not worn as the nasal route was the chosen route for intubation. Measurements were made at the trachea and in the right middle lobe or lingula after tenacious secretions had been cleared using normal saline. A catheter (internal diameter $1.0 \mathrm{~mm}$ ) was passed through the working channel of the fibreoptic bronchoscope (Olympus Model B 20D; Keymed Medical Equipment, Southend-on-Sea, UK). Tenacious secretions were removed as these could affect NO measurements by blocking the catheter. To further clear the catheter, $50 \mathrm{~mL}$ of air was passed through it by means of a three-way tap prior to on-line recordings. Ambient NO levels were recorded on the day of each bronchoscopy. 


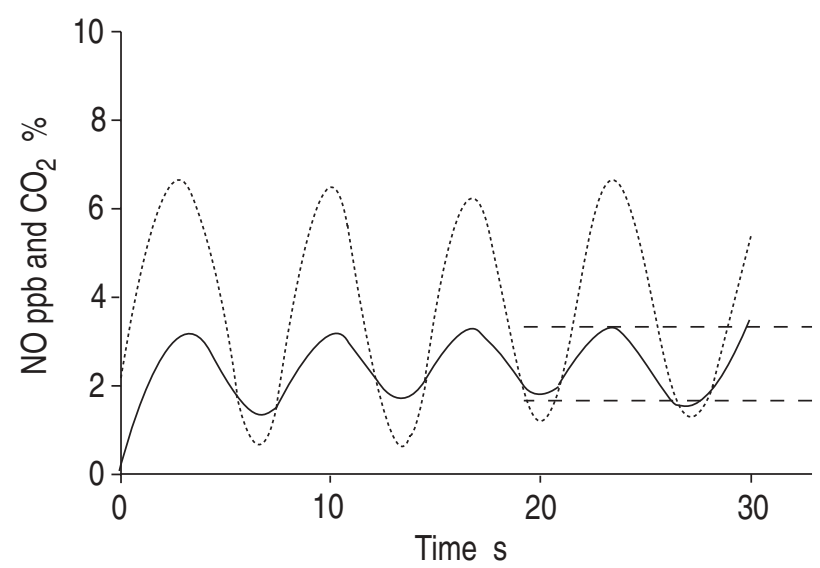

Fig. 2. - Simultaneous tracings of lower airway nitric oxide (NO; $\longrightarrow$ ) and $\mathrm{CO}_{2}(\ldots \ldots-\ldots)$ recorded at bronchoscopy. Allowing for the greater delay time of the NO analyser, the recordings show typical NO endinspiratory peak and end-expiratory troughs (indicated schematically by the upper and lower horizontal dashed lines, respectively). ppb: parts per billion.

Due to the rapid response time of the analyser and provided the patient's respiratory frequency was $<20$ breaths. min $^{-1}, \mathrm{NO}$ and $\mathrm{CO}_{2}$ levels could be recorded on-line with peaks and troughs of both $\mathrm{NO}$ and $\mathrm{CO}_{2}$. Allowing for the different delay times of the $\mathrm{NO}$ and $\mathrm{CO}_{2}$ analysers, the $\mathrm{NO}$ cycles correspond to the respiratory cycle (fig. 2). This allowed direct comparisons to be made at end-exhalation between lower airway levels and levels recorded during a single-breath manoeuvre.

\section{Reproducibility and repeatability analysis}

NO measurements were made at three points on the exhaled test as described previously. At each of these points, three measurements were obtained each day and, as per British Thoracic Society guidelines [23], the two closest NO measurements for each point were compared with each other using the method of Bland and Altman [24] to determine the coefficient of reproducibility. To de-termine the day-to-day variability for each measurement, the mean for each measurement on a given day, was similarly compared with the mean measurement obtained on the subsequent day. In a similar way, to determine if there were significant differences in NO levels at the three points chosen, the mean measurement at each point on a single day was compared with the mean measurement for each other point.

To determine whether exhaled NO measurements at the mouth were representative of levels found in the lower airways, measurements corresponding to end-exhaled $\mathrm{CO}_{2}$ obtained at the trachea and bronchial tree at bronchoscopy were compared to measurements of exhaled NO corresponding to end-tidal $\mathrm{CO}_{2}$ by univariate regression analysis with NO levels at the mouth as the dependent variable.

\section{Results}

For all single-breath tests performed, NO levels at MP, $\mathrm{CO}_{2}$ and NOp were (mean (SEM)) $6.56(0.62), 6.47(0.61)$ and $6.18(0.633) \mathrm{ppb}$, respectively. The individual reproducibility of measurements performed sequentially on the same day at each point was determined by calculating the coefficient of reproducibility. The mean \pm SD of the differences between the measurements was $0.11 \pm 0.18$ for MP, $0.095 \pm 0.16$ for $\mathrm{CO}_{2}$ and $0.094 \pm 0.13$ for NOp. The coefficients of reproducibility were $0.36 ; 0.32$; and $0.26, \mathrm{ppb}$ respectively.

The individual day-to-day repeatability for each point was also determined. The mean \pm SD of the differences between NO levels at MP, $\mathrm{CO}_{2}$ and NOp were $0.18 \pm 0.76$, $0.19 \pm 0.78$ and $0.17 \pm 0.8 \mathrm{ppb}$, respectively. Coefficients of reproducibility were $1.52 \mathrm{ppb}$ for $\mathrm{MP}, 1.56 \mathrm{ppb}$ for $\mathrm{CO}_{2}$, and $1.60 \mathrm{ppb}$ at NOp.
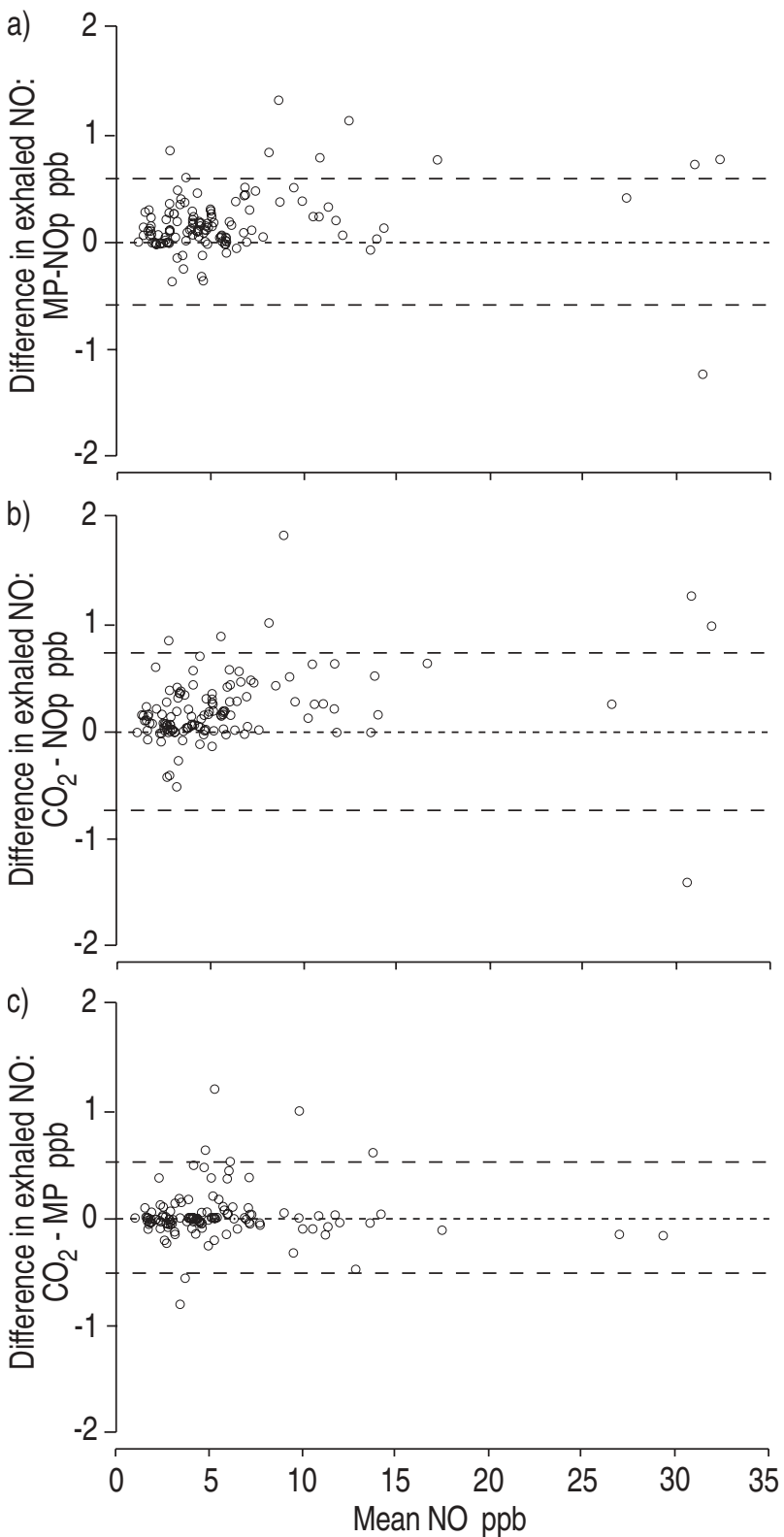

Fig. 3. - Agreement between individual nitric oxide (NO) measurements performed at the level corresponding with: a) time mouth pressure fell to below $4 \mathrm{cmH}_{2} \mathrm{O}(\mathrm{MP})$ vs the plateau of $\mathrm{NO}(\mathrm{NOp}) ; \mathrm{b}$ ) endexhaled $\mathrm{CO}_{2}\left(\mathrm{CO}_{2}\right)$ vs NOp; and c) $\mathrm{CO}_{2}$ vs MP. ....... : mean; -- - - : mean plus or minus 2sD. ppb: parts per billion. 
Ambient NO levels were not correlated with any measure of NO recorded during a single-breath manoeuvre $\left(\mathrm{r}^{2}=\right.$ $0.14, \mathrm{p}=0.46$ ) and changes in ambient $\mathrm{NO}$ concentration did not influence individual NO levels performed on separate days $\left(r^{2}=0.11, p=0.57\right)$. Ambient $N O$ levels did not correlate with the peak $\left(\mathrm{r}^{2}=0.03, \mathrm{p}=0.53\right)$ or trough $\left(\mathrm{r}^{2}=\right.$ $0.01, p=0.65$ ) NO levels measured at bronchoscopy.

For the group, NO levels recorded at $\mathrm{MP}$ and $\mathrm{CO}_{2}$ were not significantly different from each other but both were significantly greater than NO levels at NOp (paired t-test; MP vs $\mathrm{CO}_{2}, \mathrm{p}=0.4$, MP vs NOp, $\mathrm{p}<0.0001, \mathrm{CO}_{2}$ vs $\mathrm{NOp}$, $\mathrm{p}<0.0001)$. The agreement for individuals between each point is shown in figure 3 . The mean \pm SD of differences between each point was $0.18 \pm 0.32 \mathrm{ppb}$ for MP and NOp, $0.2 \pm 0.37 \mathrm{ppb}$ for $\mathrm{CO}_{2}$ and $\mathrm{NOp}$ and $0.02 \pm 0.27 \mathrm{ppb}$ for $\mathrm{CO}_{2}$ and MP. Levels measured at NOp were lower in most individuals than levels measured at either $\mathrm{MP}$ and $\mathrm{CO}_{2}$.

NO levels recorded at the lower airways of the lung transplant recipients revealed end-inspiratory peaks and end-expiratory troughs. Due to the nature of bronchoscopy in transplant recipients, the inspired oxygen concentration delivered was not the same in all subjects; however, altering the inspired oxygen concentration in an individual did not affect peak or trough levels. There was poor individual correlation between peak and trough levels $\left(\mathrm{r}^{2}=0.23, \mathrm{p}=\right.$ 0.2 ) and between peak levels and levels corresponding to end-exhaled $\mathrm{CO}_{2}$ measured at the mouth $\left(\mathrm{r}^{2}=0.12, \mathrm{p}=\right.$ $0.28)$. However, we demonstrated a clear relationship between $\mathrm{NO}$ levels recorded at end-exhaled $\mathrm{CO}_{2}$ during a single-breath manoeuvre and trough levels recorded in the
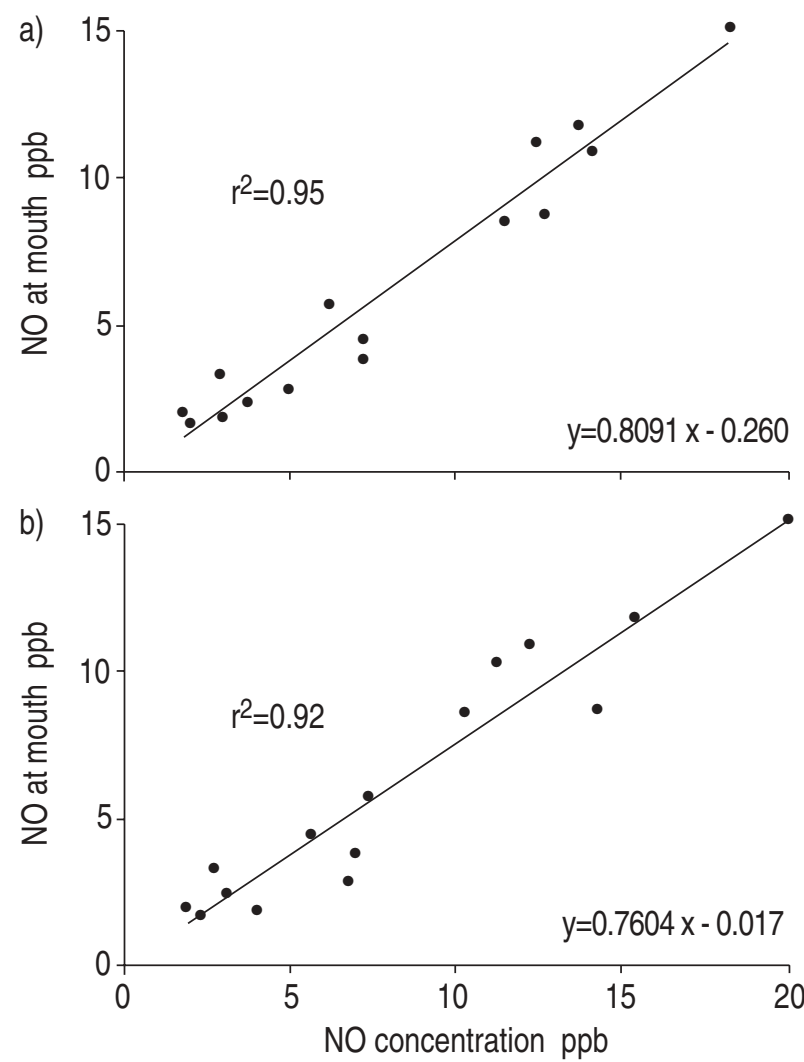

Fig. 4. - Relationship between nitric oxide (NO) levels recorded at end-exhaled $\mathrm{CO}_{2}$ during a single-breath manoeuvre (mouth) and NO level recorded at end-exhaled $\mathrm{CO}_{2}$ at: a) the trachea; and b) the bronchus. ppb: parts per billion. lower airways as shown in figure 4 (mouth $v s$ trachea $\mathrm{r}^{2}=$ $0.95, \mathrm{p}<0.0001$; mouth $v s$ bronchus $\mathrm{r}^{2}=0.92, \mathrm{p}<0.0001$ ). Trough levels recorded at the bronchus and trachea were not significantly different (mean (SEM); 8.47 (1.4) vs 846 (1.4), $\mathrm{p}=0.63$ paired $\mathrm{t}$-test $)$ and highly correlated $\left(\mathrm{r}^{2}=0.92\right.$, $\mathrm{p}<0.0001)$.

\section{Discussion}

We found that exhaled NO measurements recorded at the mouth during a single-breath manoeuvre with a rapid chemiluminescence analyser are highly reproducible, show little day-to-day variability when subjects are in a stable clinical state and, by comparing end-exhaled levels, that changes in single-breath NO measurements reflect changes in lower airway NO concentrations.

We used a standardized single-breath manoeuvre as recommended in the ERS guidelines [15], ensuring a constant expiratory flow rate of $250 \mathrm{~mL} \cdot \mathrm{s}^{-1}$ and closure of the soft palate and recorded levels along the plateau phase to avoid the influence of nasal contamination and potential influence of breathhold [19, 25] and gender [26] on peak levels. We found NO levels in healthy controls to be in the order of 6-6.5 ppb, in keeping with other studies in which the manoeuvre was performed in a similar way $[18,19$, 22]. Although our controls were free of respiratory symptoms or history of respiratory disease, they did not have formal tests of hyperresponsiveness performed prior to the study. Four subjects recorded levels $>25$ ppb suggesting asymptomatic inflammatory activity within their airways. However, removal of these subjects from the analysis did not significantly alter our findings.

At each point along the "plateau" phase, exhaled NO levels performed sequentially on the same day were highly reproducible. The mean and standard deviation of differences was within the sensitivity of the analyser. The coefficients of reproducibility were $<10 \%$ as recommended. These findings clear some of the confusion about determination of the exhaled NO value from the single-breath exhaled tracing.

The small day-to-day variability seen in stable subjects was too small to negate the value of sequential NO measurements in the monitoring of lower airway inflammation in an individual.

The individual day-to-day variability that we found was in the order of $0-2 \mathrm{ppb}$ and is significantly smaller than changes seen with disease. Subjects with bronchiectasis and upper respiratory tract infections have exhaled NO levels which are on average four times higher than controls $[10,12]$ and asthmatic subjects have end-exhaled levels 20-40 ppb higher than controls [19]. The explanation for the variability seen in control subjects is unclear, although it was not explained by changes in ambient NO levels. It remains possible that although our subjects were free of respiratory symptoms, they may have been developing an upper respiratory infection on one of the two days. Dilon et al. [17] reported a greater individual variability in five subjects tested on consecutive days. However, they sampled NO which had been breathed into a reservoir bag with resultant variable loss of reactive NO and consequently their results are not applicable to singlebreath tests performed with a rapid analyser. We have found that a baseline NO level in health can be defined in 
an individual which can be used to monitor changes in disease activity or effectiveness of anti-inflammatory treat-ment

The single-breath test is usually characterized by a short peak and longer plateau. The shape of the "plateau" phase varies between individuals yet in most is curvilinear as evidenced by the differences we found at three points. In most subjects, levels were lowest at the NO plateau and slightly higher at MP and $\mathrm{CO}_{2}$, most likely as a result of the reduced expiratory flow rate which occurs at the end of exhalation. Although differences were small, our results highlight the need for authors to define precisely from where along the exhaled test the measurement has been taken.

To our knowledge, previously published bronchoscopic recordings of NO have not been performed with a rapid analyser that allows on-line measurements of tidal breathing. As a result, previous comparisons between single-breath measurements and measurements in the lower airways have been inconclusive [17, 19, 20]. We found that lower airways NO concentrations change with tidal breathing, increasing through inspiration and decreasing through expiration. Clearing of tenacious secretions resulted in an increase in recorded NO levels. This observation may explain why, despite the fact that cystic fibrosis (CF) is characterized by airway inflammation, single-breath exhaled levels are paradoxically low [27]. There is disagreement as to the cause of these low exhaled NO measurements in CF. Recent studies have suggested that there is increased nitric oxide synthase activity in the lung of CF patients [28] but it is not detected in exhaled breath. Our results are consistent with the view that it is diffusion of NO from the epithelium which is impaired by thick, tenacious airway secretions.

We found a consistent relationship between end-exhaled NO levels in the lower airways and at the mouth. In individuals, we did not expect nor did we find these levels to be equivalent as the flow rates were different and not easily controlled by the practical limitations of bronchoscopy. For this reason we did not perform a test of agreement as defined by Bland and Altman [24]. Rather, on univariate analysis with single-breath NO levels as the dependent variable, we found that a relationship between end-exhaled NO levels in the lower airways and at the mouth could be clearly defined. The degree of correlation suggests that changes in NO levels at the mouth are highly representative of changes in NO concentration in the lower airways and lend further support to the contention that the single breath test is a valuable measure of lower airways inflammation.

Although it remains uncertain, our findings give some insight into the source of NO found in the lower airways. KHARITINOV and BARNES [21] have shown that during normal tidal breathing but not during breathing against resistance, argon delivered to the nose could be sampled in the lower airways. If possible, nasal contamination of the lower respiratory tract is excluded by an inflated endotracheal tube [29], then NO is still detected in air sampled directly from the lower respiratory tract. The cyclical levels of NO that we found in the lower airways suggest that during the inspiratory phase of tidal breathing there is auto-inhalation of NO from the nasopharynx. However, we found a poor correlation between peak (end-inspiratory) and trough (end-expiratory) levels, suggesting that auto-inhalation does not contribute significantly to trough levels. Therefore, we believe that trough levels predominantly reflect lower airway NO production, as has been suggested by others $[18,19]$.

Our data support the measurement methodology described in the recent ERS guidelines [15], apart from the use of noseclips, which we feel prevents the subject from inhaling via the nasal route, thus contaminating the first part of the exhalation. The use of noseclips in our subjects reduced the time taken to reach steady state and made the NO plateau phase longer.

In summary, we have shown that a standardized singlebreath test is reproducible and in most healthy controls has little day-to-day variability. Providing that subjects maintain a mouth pressure sufficient to close the soft palate and flow is kept constant throughout the test, then nitric oxide levels recorded at the mouth are closely related to levels in the lower airways. Our findings lend added support to suggestions in the European Respiratory Society guidelines [15] that the single-breath test is a valid noninvasive measure of lower airways inflammation that can be used to monitor disease and effects of therapy.

\section{References}

1. Furchgott RF, Zawadski JV. The obligatory role of endothelial cells in the relaxation of arterial smooth muscle by acetylcholine. Nature 1980; 288: 373-376.

2. Ignarro LJ, Buga GM, Wood KS, Byrns RE, Chaudhuri G. Endothelium-derived relaxing factor produced and released from artery and vein is nitric oxide. Proc Natl Acad Sci USA 1987; 84: 9265-9269.

3. Dinh-Xuan AT. Endothelial modulation of pulmonary vascular tone. Eur Respir J 1992, 5: 757-762.

4. Belvisi MG, Stratton CD, Barnes PJ. Nitric oxide is the neurotransmitter of bronchodilator nerves in human airways. Eur J Pharmacol 1992; 210: 221-222.

5. Nussler AK, Billiar TR. Inflammation, immunoregulation and inducible nitric oxide synthase. J Leuk Biol 1993; 54: 171-178.

6. Hibbs JB Jr. Synthesis of nitric oxide from L-arginine: a recently discovered pathway induced by cytokines with antitumour and antimicrobial activities. Res Immunol 1991; 142: $257-258$

7. Lundberg JON, Weitzberg E, Lundberg JM, Alving K. Nitric oxide in exhaled air. Eur Respir J 1996; 9: 26712680.

8. Kharitonov SA, Yates D, Robbins RA, Logan-Sinclair R, Shinebourne EA, Barnes PJ. Increased nitric oxide in exhaled air of asthmatic patients. Lancet 1994; 343: 133 135.

9. Persson MG, Zetterstrom O, Agrenius V, Ihre E, Gustafsson LE. Single breath nitric oxide measurements in asthmatic patients and smokers. Lancet 1994; 343: 146-147.

10. Kharitonov SA, Wells AU, O'Connor BJ, et al. Elevated levels of exhaled nitric oxide in bronchiectasis. Am J Respir Crit Care Med 1995; 151: 1889-1893.

11. Cremona G, Higgenbottam T, Borland C, Mist B. Mixed expired nitric oxide in primary pulmonary hypertension in relation to lung diffusion capacity. $Q J$ Med 1994; 87: 547-551.

12. Kharitonov SA, Yates D, Barnes PJ. Increased nitric oxide in exhaled air of normal human subjects with upper respiratory tract infections. Eur Respir J 1995; 8: 295 297. 
13. Yates D, Kharitonov SA, Robbins RA, Thomas PS, Barnes PJ. Effect of a nitric oxide synthase inhibitor and a glucocorticosteroid on exhaled nitric oxide. Am J Respir Crit Care Med 1995; 152: 892-896.

14. Barnes PJ, Kharitonov SA. Exhaled nitric oxide: a new lung function test. Thorax 1996; 51: 233-237.

15. Kharitonov S, Alving K, Barnes PJ. Exhaled and nasal nitric oxide measurements: recommendations (ERS Task Force Report). Eur Respir J 1997; 10: 1683-1693.

16. Brett SJ, Evans TW. Endogenous nitric oxide in exhaled human breath: a new means of monitoring airway disease or another NO-NO. Chest 1996; 110: 873-874.

17. Dillon WC, Hampl V, Schultz PJ, Rubins JB, Archer SL. Origins of breath nitric oxide in humane. Chest 1996; 110: 930-938

18. Robbins RA, Floreani AA, Von Essen SG, et al. Measurement of exhaled nitric oxide by three different techniques. Am J Respir Crit Care Med 1996; 153: 1631-1635.

19. Kharitonov SA, Fan Chung K, Evans D, O'Connor BJ, Barnes PJ. Increased exhaled nitric oxide in asthma is mainly derived from the lower respiratory tract. Am J Respir Crit Care Med 1996; 153: 1773-1780.

20. Gerlach H, Rossaint R, Pappert D, Knorr M, Falke KJ. Autoinhalation of nitric oxide after endogenous synthesis in nasopharynx. Lancet 1994; 343: 518-519.

21. Kharitonov SA, Barnes PJ. There is no nasal contribution to exhaled nitric oxide during exhalation against resistance or during breath-hold. Thorax 1997; 52: 540-544.

22. Silkoff PE, McLean PA, Slutsky AS, et al. Marked flow-dependence of exhaled nitric oxide using a new technique to exclude nasal nitric oxide. Am J Respir Crit Care Med 1997; 155: 260-267.

23. BTS/ARTP Liason Committee. Guidelines for the measurement of respiratory function. Recommendations of the British Thoracic Society and the Association of Respiratory Technicians and Physiologists. Respir Med 1994; 88 : 165-194.

24. Bland JM, Altman DG. Statistical methods for assessing agreement between two methods of clinical measurement. Lancet 1986; (i): 307-310.

25. Persson MG, Wiklund NP, Gustafsson LE. Endogenous nitric oxide in single exhalations and the change during exercise. Am Rev Respir Dis 1993; 148: 1210-1214.

26. Kharitonov SA, Logan-Sinclair RB , Busset CM, Shinebourne EA. Peak expiratory nitric oxide differences in men and women: relation to the menstrual cycle. Br Heart J 1994; 72: 243-245.

27. Ho LP, Innes JA, Greening AP. Exhaled nitric oxide (NO) is not elevated in patients with cystic fibrosis or bronchiectasis compared to normals. Thorax 1996; 51(Suppl. 3) A19 (abstract).

28. Belvisi M, Barnes PJ, Larkin S, et al. Nitric oxide synthase activity is increased in inflammatory lung disease in humans. Eur J Pharmacol 1995; 283(1-3); 255-258.

29. Massaro AF, Metha S, Lilly CM, Kobzik L, Reilly JJ, Drazen JM. Elevated nitric oxide concentrations in isolated lower airway gas of asthmatic subjects. Am J Respir Crit Care Med 1996; 153: 1510-1514. 